\title{
Refugee Impacts in Hosting Countries- Solid waste Management in Amman city as a Case Study
}

\author{
Mohammad K. Younes ${ }^{1}$, Ghassan A. Al-Dulaimi ${ }^{1}$ \\ ${ }^{1}$ Faculty of Engineering, Department of Civil Engineering, Philadelphia University, P.O.Box:19392 \\ Amman - Jordan mohyoumoh@hotmail.com
}

\begin{abstract}
Solid waste management is a major challenge for societies especially in the developing countries. For municipalities solid waste management consumes more than half of the allocated financial resources. However, the number of immigrants has been increased rapidly in the recent years due to political instability around the world. Sudden population increase due to immigration will confuse the decision making process and overburden the current infrastructure. Thus there is a great demand to develop a scientific approach to absorb such sudden increments and to properly develop future plans. In addition, most of the immigrants hosting societies are developing countries, that are classified as poor to mid income countries which overburdens them. This study aims to highlight and analysis the impacts of immigration on the solid waste management in the hosting communities. In addition, it will make recommendations to minimize the refugee impacts. In order to collect the data for estimating the human and financial impacts an internet research and stakeholders interviews were performed. Solving the political conflicts under the umbrella of the United Nation and giving the support for the people in their home countries will minimize the immigration movements thus reduces the refugee impacts.
\end{abstract}

Keywords: Solid Waste Management, Refugee and Solid Waste, Refugee Impacts on Solid Waste

\section{Introduction}

Large quantities of waste from various sources are generated annually. Proper solid waste management plays essential role for protecting both human health and the environment (Younes et al. 2016). However, the world nowadays witnesses the largest number of displaced people from their home since World War II (Betts and Collier 2015). These people cause a huge overburden on the hosting communities. In addition, more than $90 \%$ of these refugees live in developing countries with limited infrastructure and human capacities, and more than half of the refugee population live in urban area. Furthermore, Middle East and North Africa hosts about $60 \%$ of the total refugee (Ward 2014), and majority of them are under age and women who need extensive care and proper primary education (UNHCR 2016).

Furthermore, according to UNHCR (2016) around 34,000 capita has been displaced from their homes due to war, persecution or political instability every day creating extra pressure on the infrastructure of hosting communities. The refugees may boost the economy in developed and rich countries through offering cheap and trained workers, while it has a negative impacts at developing poorer hosting communities by competition on limited resources and increasing the prices (Maystadt and Verwimp 2014). However, the refugee affects are not limited to infrastructure but it is extended to social, technical, economical, environmental and health impacts.

Many studies were tackled the refugee crises from various aspects especially in the recent years. However, very little is known about the technical, financial and social impacts on local hosts (Maystadt and Verwimp 2014). For instance, Fisk (2016) analysed the security challenges that face the refugees in African hosting societies (Fisk 2016). The public health and risks associated to migration are analysed by (Morabia and Benjamin 2015). They indicate the losses of origin poor countries and the gains of hosting rich countries by getting young and productive migrants. In addition, the emergence, due to lack of health control, of a coetaneous leishmaniasis epidemic in Syria is analyzed by (Al-Salem et al. 2016). However, the capacity of country to host a refugee was assessed using a physical and economical data. Furthermore, an optimum refugee distribution among countries could be achieved using an agent based model (Hattle, Yang, and Zeng 2016).

Solid waste management is one of the major challenges in developing countries. Moreover, it accounts for more than half of municipalities budgets in these countries (Al-Khatib and Arafat 2010). Thus there is an urgent 
demand to perform deep impact analysis of refugees on solid waste management activities. This study aims, to show the financial and technical impacts of migration on solid waste management. This will help the decision makers properly estimate the associated costs and develop sustainable waste management plans (Zurbrügg, Caniato, and Vaccari 2014).

\section{Methodology}

Data about the refugee number and their distribution in Jordan and in Amman city was collected from the Department of Statistics (DOS). In addition, a survey was prepared to collect a data related to solid waste management and its activities costs, then personal interviews for the stakeholders in Greater Amman Municipality (GAM) were conducted to obtain the required information. Finally, migration impacts and data are collected from literatures and UNHCR web site, respectively.

\section{Results and Discussions}

Refugee distribution around the world is shown in Figure (1). Around 68\% of the refugees are being hosted in Middle East and Africa. However, the Middle East and North Africa are places for refugee hosting, which creates extra pressure on originally unstable area. According to DOS the total population in Jordan is 9.53 millions. Jordan hosts refugee mainly from Palestine, Syria and Iraq. Table (1) represents facts regarding the refugee in the world and in Jordan.

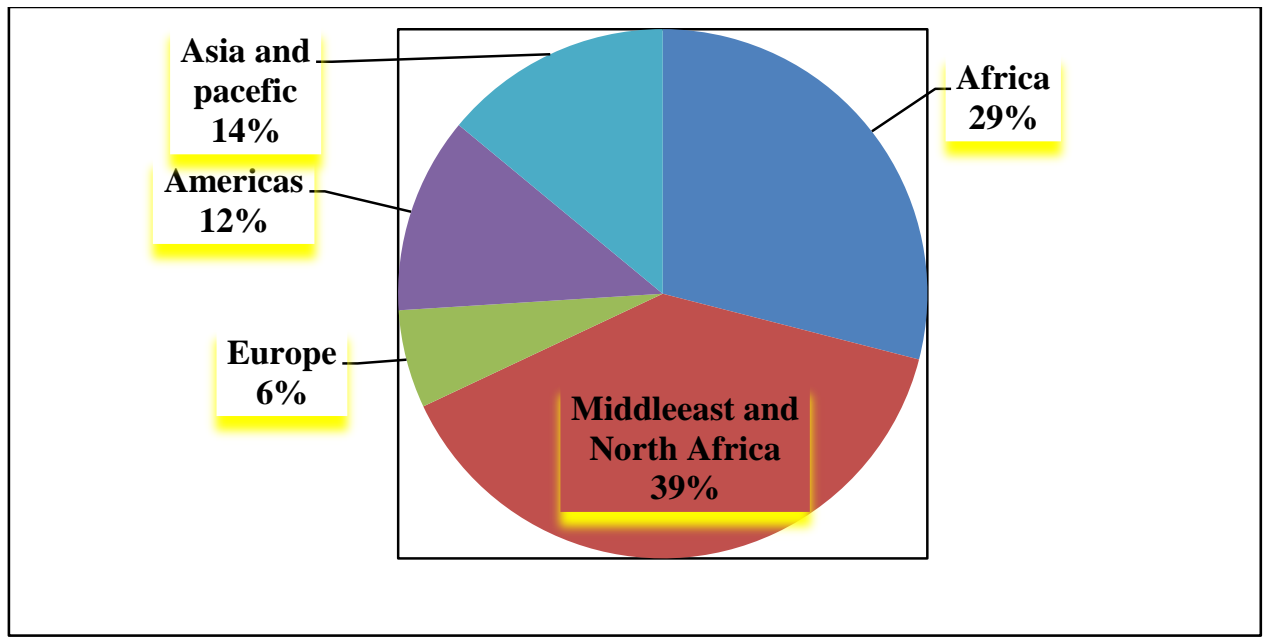

Fig. 1: Refugee distribution in the world, Source: UNHCR 2016

TABLE 1: Refugee Facts From The World and Jordan

\begin{tabular}{lclc}
\hline \hline Fact (worldwide) & $\begin{array}{c}\text { Number } \\
\text { (Million) }\end{array}$ & Fact from Jordan & $\begin{array}{c}\text { Number } \\
\text { (Million) }\end{array}$ \\
\hline $\begin{array}{l}\text { No of people forced to leave their home } \\
\text { Registered refugee }\end{array}$ & 65.3 & Number of Non Jordanian & 2.9 \\
Refugee under 18 years & 21.3 & Registered refugee & 2.8 \\
UNHCR refugee mandate & 11 & Refugee under 18 years & 0.664 \\
$\begin{array}{l}\text { UNRWA } \\
\text { ( Palestinian refugee) }\end{array}$ & 16.1 & UNHCR refugee mandate & 2.14 \\
Stateless people & 5.2 & UNRWA & (Palestinian refugee) \\
No of displaced people daily & 10 & Number of camps under UNHCR & 3
\end{tabular}

${ }^{a}$ United Nation Relief and Works Administration for Palestinian Refugee (UNRWA) Sources:(UNHCR 2016) (UNRWA 2016) 
Stateless people who has been denied a nationality and thus they don't have basic human rights such as education and proper health care. However, $54 \%$ of the world refugees are from Syria, Afghanistan and Somalia with refugee number of 4.9, 2.7 and 1.1 million refugees, respectively. Around $30 \%$ (2.8 million) of the Jordanian population is registered as refugee either under UNRWA or UNHCR, most of them live in urban area. However, in Jordan there are 13 camps for refugee. Ten camps are under UNRWA responsibility with total population around 370,000 capita, half of them are under 18 years old. The responsibility of solid waste collection from Palestinian refugee camps is of UNRWA. It's role extends to deliver the generated municipal solid waste to the nearest landfill or transfer station, then the role of municipality, as transfer station operator, or common council service, as landfill operator, begins.

The UNHCR camps are Zaatari camp in Mafraq governorate, Azraq camp in Zarqa governorate and Emirates Jordanian Camp (EJC) in Zarqa governorate too. These camps host in total about 113,000 capita distributed as 77,780 in Zaatari; 28,255 in Azraq and 6,277 refugee in EJC. The solid waste collection in Zaatari and Azraq camps is done by privet collector but it is supervised by ACTED, the French NGO. However, as shown in Figure (2) all the refugee camps (UNRWA and UNHCR) are located in central and northern regions of Jordan, mainly in Amman, Zarqa, Jerash and Irbid Cities.

Jordan witnesses rapid municipal solid waste generation increments due to population growths and unexpected migration (Younes et al. 2013). The solid waste generation rate in urban area is about $1 \mathrm{~kg}$ per capita per day, while it is around $0.6 \mathrm{~kg}$ per capita per day in rural area. In Jordan, Solid waste management is the responsibility of individual municipalities. Each one should collect then transport the waste to a transfer station or landfill for disposal. However, refugee camp produces concentrated solid waste and thus the collection frequency of generated solid waste should be high. In addition, the camp area usually is small and roads within it are narrow which requires special attention to generation, collection and health effects of the waste. According to ministry of environment the rate of solid waste collection is $90 \%$ in urban area and $70 \%$ in rural area. However, Figure (3) shows the monthly solid waste generation between 2010-2015. The figure shows the solid waste amount that sent to Al-Gabawi landfill from Amman city.

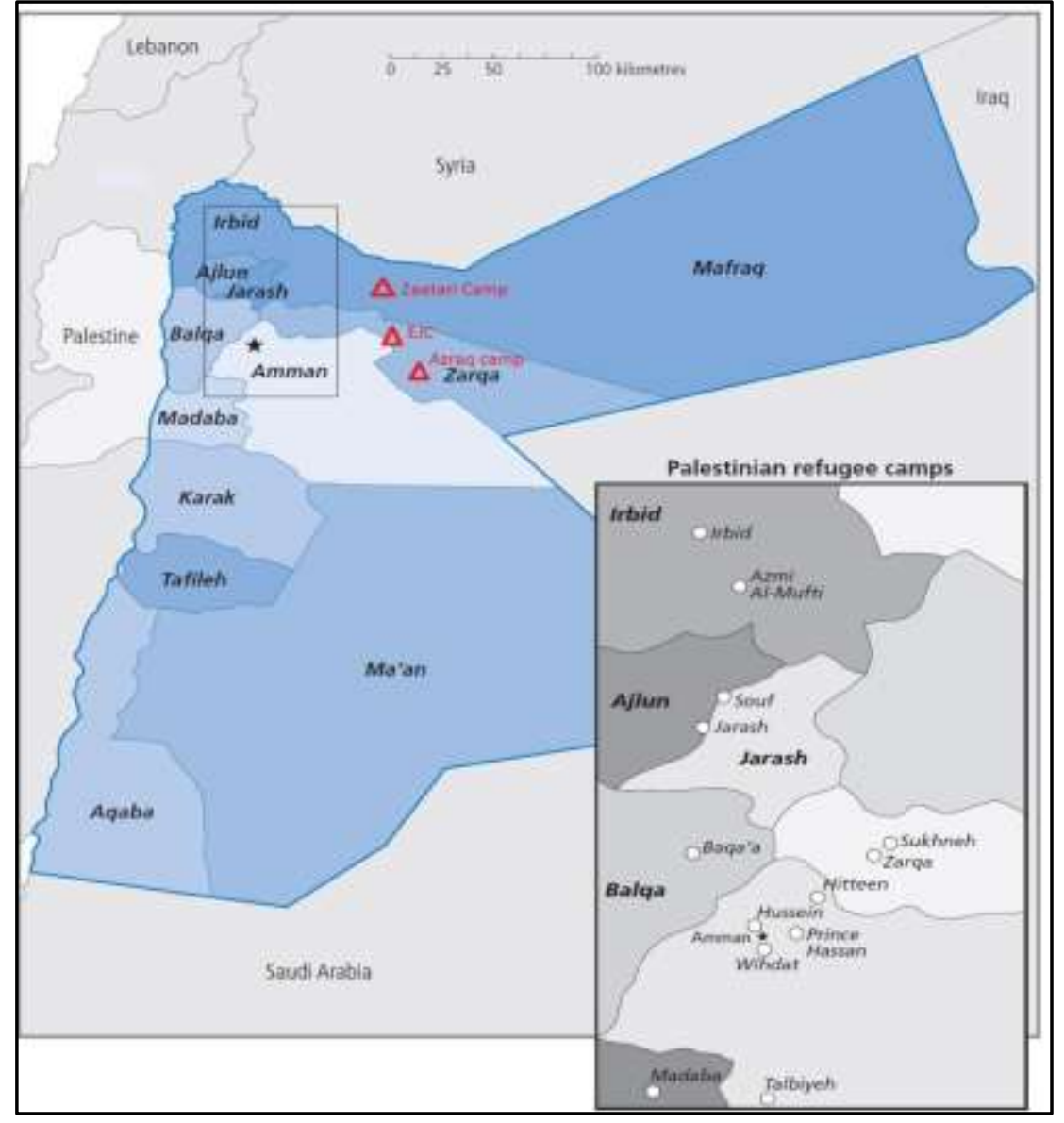

Fig. 2: Refugee camps in Jordan 


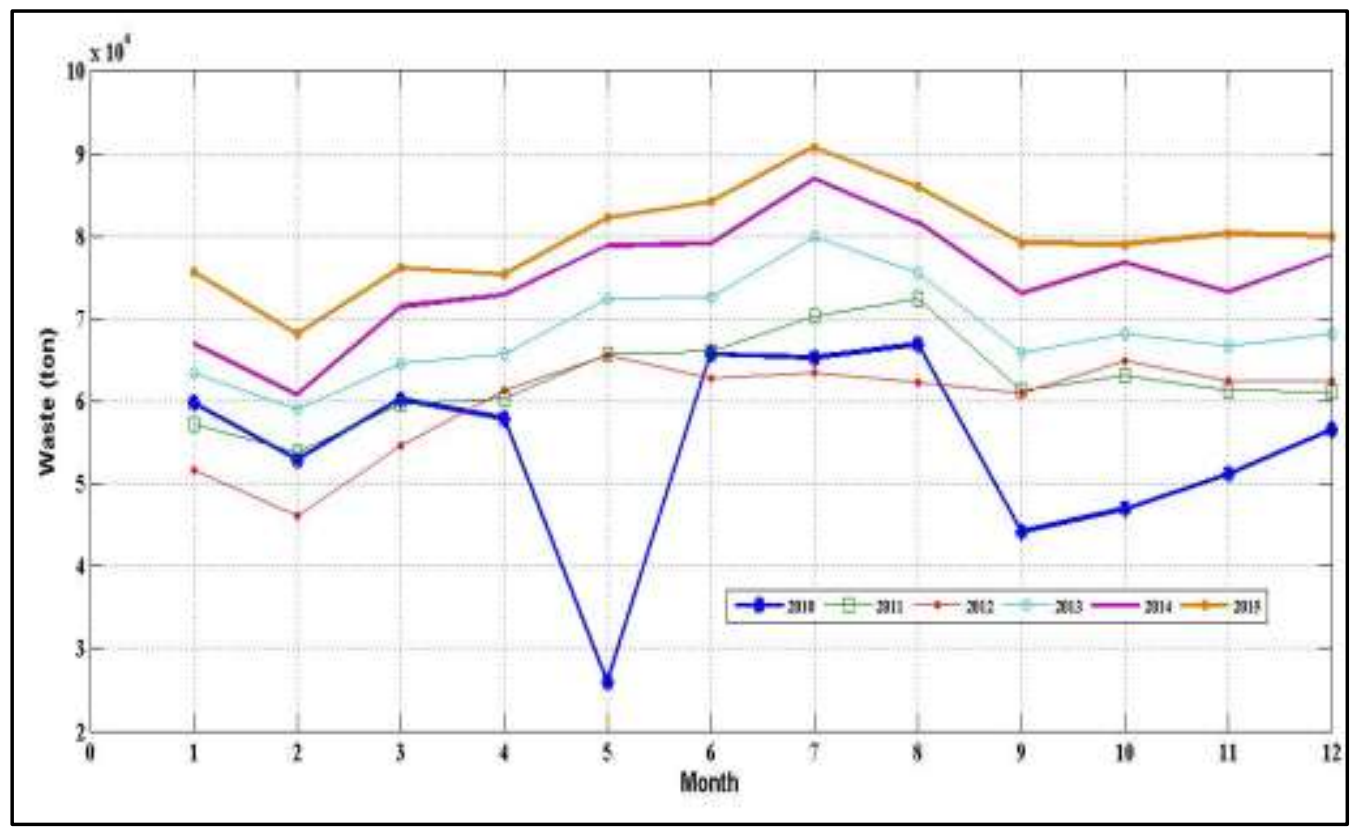

Fig. 3: Monthly solid waste generation in Amman city 2010-2015

According to the department of statistics the population growth rate in Jordan is about $3 \%$, but due to immigration impacts it is increased to around 5.3\% (DOS 2015). On the other hand, the average solid waste generation growth for the period 2010-2015 is around 8\%. However, the maximum growth was in the year 2013, it is about 16\%, due to the highest Syrian immigration movement in this year. In addition, before the Syrian crises, especially in the years 2011 and 2012, the solid waste generation was almost constant except for few months. Furthermore, the year 2010 witnessed the highest variations in waste generation due to frequent shutdown in the bridge weight at the landfill.

Finally, it is estimated that in Amman city there is around 1.3 million refugee live in camps and in urban region. Considering the average Jordanian solid waste generation rate, which is $1 \mathrm{~kg}$ per capita daily, the estimated extra solid waste is about 1,300 ton per day. According to GAM the collection cost of solid waste is around 36JD per ton. This cost includes labour, logistic and machines costs. In addition, the cost of solid waste disposal at Al-Gabawi landfill excluding the land price is 10.5 JD. This cost covers the workers, land preparation like lining, and further monitoring and control like leachate collection and treatment. However, the total cost including the land price may exceed the $50 \mathrm{JD}$ per ton. Considering the minimum solid waste cost, it is estimated the extra solid waste cost due to refugee in Amman city alone is about 23.75million annually, which is considered big number for a city in developing country.

\section{Conclusions}

Migration is the new challenge that faces the humanity today, and the entire world shares the responsibility to solve and minimize its impacts. Refugee increases the pressure on the infrastructure in the hosting communities. Distributing the refugee among various urban areas minimizes the pressure on infrastructure. However, refugee camps usually occupy small area but it has a large number of populations, thus it is important to properly plan the primary services. However, to reduce the immigration impacts it is recommended to solve the conflicts and protect human in conflicting areas and help them to stay at their homes. Proper distribution for migrant people will balance the pressure on infrastructure and helps the developing countries. In addition, sharing the human responsibility and support the hosting communities not only financially but with knowledge and required expertise are highly demanded to help them absorb the refugee overburden.

\section{Aknowledgment:}

The authors thank Philadelphia University for supporting this research. 


\section{References}

[1] Al-Khatib, Issam A, and Hassan A Arafat. 2010. "A review of residential solid waste management in the occupied Palestinian Territory: a window for improvement?" Waste Management \& Research 28 (6):481-488.

[2] Al-Salem, Waleed S, David M Pigott, Krishanthi Subramaniam, Lee Rafuse Haines, Louise Kelly-Hope, David H Molyneux, Simon I Hay, and Alvaro Acosta-Serrano. 2016. "Cutaneous leishmaniasis and conflict in Syria." Emerging infectious diseases $22(5): 931$.

[3] Betts, Alexander, and Paul Collier. 2015. "Help Refugees Help Themselves: Let Displaced Syrians Join the Labor Market." Foreign Affairs 94:84.

[4] DOS, Department of Statistics. 2015. "Report the main results of the General Census of Population and Housing, Jordan."11-16.

[5] Fisk, Kerstin. 2016. "One-sided Violence in Refugee-hosting Areas." Journal of Conflict Resolution:0022002716656447.

[6] Hattle, Anna, Katherine Shulin Yang, and Sicheng Zeng. 2016. "Modeling the Syrian Refugee Crisis with Agents and Systems." UMAP Journal 37 (2).

[7] Maystadt, Jean-François, and Philip Verwimp. 2014. "Winners and losers among a refugee-hosting population." Economic development and cultural change 62 (4):769-809.

[8] Morabia, Alfredo, and Georges C Benjamin. 2015. "The Refugee Crisis in the Middle East and Public Health." American journal of public health 105 (12):2405-2406.

[9] UNHCR, United Nations High Commissioner for Refugees. 2016. "Figures at a Glance."

[10] UNRWA, United Nations Relief and Works Agency for Palestinian Refugees in the Near East. 2016. doi: https://www.unrwa.org/where-we-work/jordan.

[11] Ward, Patricia. 2014. "Refugee cities: Reflections on the development and impact of UNHCR urban refugee policy in the Middle East." Refugee Survey Quarterly 33 (1):77-93.

[12] Younes, Mohammad K, ZM Nopiah, B Nadi, NE Ahmad Basri, Hassan Basri, FM Mohammed, and Khaldoun Shatanawi. 2013. "Investigation of solid waste characterization, composition and generation using management of environmental systems in Zarqa, Jordan." Asian Journal of Chemistry 25 (17):9523.

[13] Younes, Mohammad K., Z. M. Nopiah, N. E. Ahmad Basri, H. Basri, Mohammed F. M. Abushammala, and Mohammed Y. Younes. 2016. "Landfill area estimation based on integrated waste disposal options and solid waste forecasting using modified ANFIS model." Waste Management 55:3-11. doi: http://dx.doi.org/10.1016/j.wasman.2015.10.020.

[14] Zurbrügg, Christian, Marco Caniato, and Mentore Vaccari. 2014. "How assessment methods can support solid waste management in developing countries—a critical review." Sustainability 6 (2):545-570. 